\title{
Insulin response of Diabetic Pregnant Women: Analysis of saliva by FTIR study
}

\author{
R. Raziya Sultana ${ }^{1 *}$, S.N. Zafarullah ${ }^{2}$ and N. Hephzibah Kirubamani ${ }^{3}$ \\ ${ }^{1}$ Deptartment of Physics, Justice Basheer Ahmed Sayeed College for Women, Chennai-600018, India \\ ${ }^{2}$ Department of Physics, Easwari Engineering College, Chennai 600089, India \\ ${ }^{3}$ Obstetrics \& Gyneacology, Stanley Medical College \& Superintendent i/c, Govt. RSRM Lying in Hospital, Chennai- \\ 600013, India \\ saalim_raziya@yahoo.com, saalimraziya@gmail.com ${ }^{1 *}$
}

\begin{abstract}
This paper presents the FTIR spectral study of saliva of normal and diseased (diabetes) and its use in differentiating those pregnant women on insulin therapy. FTIR saliva spectra were recorded over the region $4000-400 \mathrm{~cm}^{-1}$ on a Spectrum one Perkin Elmer FTIR spectrometer. Saliva samples were collected from 20 volunteers in each set of age group 25 to 35 . From the spectral study, the absorbance values of the diseased and normal saliva samples were compared. The spectral differences of intensity ratio parameters were introduced and the results were discussed. In order to find the efficacy, the absorption values of the specific bands of the spectra of normal and diabetic pregnant women were compared and the internal ratio parameter $R_{1}\left(I_{1653} / I_{1410}\right), \quad R_{2}\left(I_{2931} / I_{547}\right), \quad R_{3}\left(I_{2931} / I_{1410}\right)$, $\mathrm{R}_{4}\left(\mathrm{I}_{2931} / \mathrm{I}_{3292}\right), \mathrm{R}_{5}\left(\mathrm{I}_{3292} / \mathrm{I}_{547}\right)$ were calculated, and the result observed for diabetic pregnant women after insulin therapy (i.e., $3 \mathrm{hrs}$ and 7 days) was almost similar to that of the normal pregnant women. Besides, the intensity of absorption peaks of the diabetic pregnant women before administration of insulin, after intake of insulin (3hrs) and after insulin therapy (7 days) were considered in which the intensity ratio parameters $R_{1}\left(I_{1544} / I_{1075}\right), R_{2}\left(I_{1544} / I_{1224}\right), R_{3}\left(I_{2931} / I_{1075}\right)$, $\mathrm{R}_{4}\left(\mathrm{I}_{3292} / \mathrm{I}_{1075}\right), \mathrm{R}_{5}\left(\mathrm{I}_{3292} / \mathrm{I}_{1224}\right)$, were calculated. The observed absorbance values increased in diabetic pregnant women initially, but slightly decreased after insulin therapy $3 \mathrm{hrs}$ and further decreased after 7 days compared to normal pregnant women. Thus, striking spectral differences (in terms of intensity value) observed between saliva of normal, diseased subjects when analysed after insulin therapy. The comparison of these values showed that the spectra of normal and diabetic pregnant women before and after therapy are different and the vibrational analyses were carried out. It is concluded that FTIR may be applied to indicate the changes in the salivary pattern of the diabetic pregnant women with insulin therapy.
\end{abstract}

Keywords: Saliva, normal pregnant women, diabetic pregnant women, insulin, FTIR spectroscopic analysis.

\section{Introduction}

The greatest challenge of salivary diagnostics is to identify disease diagnostic markers and successfully translate these research efforts from the laboratory into the clinic. To empower salivary diagnostics to become an approach for health surveillance, established robust scientific platforms for saliva biomarker discovery, validated potential candidates, and developed point-ofcare technologies for high throughput, efficiency, and accurate clinical applications. Saliva is a complex fluid containing a variety of enzymes, hormones, antibodies, antimicrobial constituents, and growth factors. (Zelles et al., 1993; Rehak et al., 2000). Today, a growing number of proof-of-principle assays have been established using saliva to monitor diseases or bodily conditions such as HIV infection (Emmons, 1997; Malamud 1997) immune responses to viral infections (e.g., hepatitis A, B, \& C), (Chaita et al., 1995; Ochnio et al.,1997; El-Medany et al., 1999) systemic levels of drugs, and the detection of illicit drug use (Cone,1993, Kidwell et al.,1998). Salivary diagnostics would enable clinicians to monitor diseases frequently and easily and would have impact on the future medical research and therapy.

Pregnancy involves complex hormonal interactions, which cause profound physiologic changes. Some changes are more evident than others. The changes that occur are the result of increasing maternal and fetal requirements for the growth of the fetus and the preparation of the mother for delivery. An increase in the secretion of female sex hormones, estrogen by 10 -fold and progesterone by 30 -fold, is important for the normal progression of pregnancy. Increased hormonal secretion and fetal growth induce several systemic, as well as local physiologic and physical changes in a pregnant woman. Changes in salivary pattern in normal and diabetic pregnant women in each trimester have been compared using FTIR spectroscopy both qualitatively and quantitatively (Raziya Sultana et al., 2011).

Early detection of disease plays a crucial role in successful therapy. Since the advantages of saliva as a diagnostic tool were revealed, the use of saliva for surveillance of disease and general health has become a highly desirable goal in healthcare research and promotion. However, the full power and potential of saliva in medical applications was only recently recognized when saliva was shown to reflect the spectrum of health and disease states and to offer distinctive advantages over serum (Slavkin, 2004; Mandel,1993). Pregnancy does not cause periodontal disease but does worsen an existing condition (Tilakaratne et al., 2000). Female sex hormones (estrogen, progesterone, and human gonadotrophin) are secreted primarily by the placenta.
Research article

(C)Indian Society for Education and Environment (iSee)
"FTIR-based fingerprinting of saliva for diabetic pregnant women" http://www.indjst.org
R. Raziya Sultana et al. Indian J.Sci.Technol. 
These hormones are responsible for most of the physiologic changes during pregnancy. The main salivary changes in pregnancy involve its flow, composition, $\mathrm{pH}$, and hormone levels.

Diabetes mellitus is a chronic illness, in which the body is exposed to continual high levels of blood glucose, a condition known as hyperglycemia. Glucose is a simple sugar and an important source of energy, especially for the brain. Almost all forms of diabetes stem from problems in the body's production and use of insulin, the hormone that is responsible for keeping blood glucose levels in check. One cause of diabetes is the inability to produce enough insulin; for this problem, treatments range from oral medications that increase insulin secretion (i.e., secretagogues, such as tolbutamide) to injections of insulin itself. Another cause of diabetes is the inability of body tissues to respond sufficiently to normal amounts of insulin, or insulin resistance.

Glucose is the source of quick energy, and we always need a certain minimum amount of glucose in the bloodstream. On the other hand, excess blood glucose can damage tissues. Insulin is the hormone that keeps blood glucose levels from getting too high, but diabetes disrupts the body's ability to use insulin effectively. Carbohydrates come in all sizes. Large carbohydrates such as polysaccharides (e.g., starch) are chains of individual sugar molecules. The smallest carbohydrates are monosaccharides, individual sugar molecules. Glucose, which is a small water-soluble molecule, is a monosaccharide (Nussey \& Whitehead, 2001). Insulin is a protein molecule made in beta cells that are clustered in islets within the pancreas. Glucose is the main stimulus for insulin secretion, but the pancreas also releases insulin in response to elevated blood levels of amino acids or when signaled by the parasympathetic (vagal) nervous system.

In this the saliva samples are collected from diabetic pregnant women of $1^{\text {st }}, 2^{\text {nd }}$ and $3^{\text {rd }}$ trimester and FTIR analysis were carried out. Early in pregnancy, increase in estrogen and progesterone level which lead to pancreatic beta cell hypertrophy and insulin excretion alters maternal carbohydrate metabolism. The placental peptide hormone human chorionic somatomamotropia known as human placental lactogen has been implicated in inducing insulin resistance as have prolactin corisol, estrogen and progesterone. The level of all these substances is significantly greater in pregnancy than in non pregnant states. Plasma cellulose responses to similar carbohydrate loads are higher in pregnant women than nonpregnant women (Frank \& Patrick Duff, 2004).

The present work is attempted in the study of changes in salivary pattern in normal and diabetic pregnant women and the response in change in saliva on insulin therapy (after $3 \mathrm{hrs}$ and after 7 days) are compared by using FTIR spectroscopy both qualitatively and quantitatively. The type of spectral signatures qualitatively differentiates the progesterone levels in pregnancy. The intensity ratio among the absorption bands characterizes it quantitatively. The present work is proposed to evaluate a new approach in the analysis of saliva in normal and diabetic pregnant women (before insulin) and the changes in salivary pattern during pregnancy and the response in change in saliva after ( 3 hrs and after 7 days) therapy in mid-IR spectroscopy.

\section{Materials and methods}

In this study, saliva samples were collected from normal and diabetic pregnant women from the Govt. RSRM Lying in Hospital, Chennai. The samples were collected from normal and diabetic pregnant women (after excluding other diseases) and the response in change in saliva of insulin therapy patients have been considered and chosen for the analysis. All the sampling procedures were performed between $12.00 \mathrm{am}$ to $1.00 \mathrm{pm}$ for uniformity, 20 samples of age group 25 to 35 were used for spectral analysis. After insulin therapy the response in diabetic patient were compared with normal patient and how long it takes for response were also analysed. In each category, diabetic pregnant women after insulin 3 hrs (since both insulin peak action in about 3-4 hours) and after insulin 7 days (to assess the control of the disease) - During the study period all diabetic pregnant women maintained in the same type of insulin. Informed consent were obtained from all subjects as approved by local ethics committee. Depending upon the blood sugar level, insulin is prescribed for the patients. In this analysis, short acting insulin and intermediate acting insulin were used. The FTIR spectral measurements of all the samples were carried out at Sophisticated Analytical Instrumentation Facility IIT, Madras, Chennai-36, using Spectrum-One Perkin- Elmer FTIR Spectrometer. The spectra are recorded in the mid infrared region of 4000 $400 \mathrm{~cm}^{-1}$ in the absorption mode. $50 \mu \mathrm{L}$ of each solution was spread evenly on the thallium bromide crystals window. The samples were air dried for water evaporation to eliminate the stray absorption bands due to water and holder was mounted in the sample window of the spectrometer. The spectrometer is equipped with a globar source, $\mathrm{KBr}$ beam splitter and DTGS cooled detector. The sampling window was scanned as the background and 32 scans are co added with a spectral resolution of $1 \mathrm{~cm}^{-1}$. All the spectra were baseline corrected and normalized to acquire identical area under the curve.

\section{Statistical analysis}

Saliva samples of normal and diabetic pregnant women were analysed by means of Statistics FTest (0.05,"Series 1","Series2") in which the parameter used was the alpha value (probability), the "first input series name" which means the name of the series object that stores the first group of data and the "second input series name" which indicates the name of the series object that stores the second group of data.

An FTestResult object, which has the following members: First series mean; Second series mean; First series variance; Second series variance; $F$ value;
Research article

(CIndian Society for Education and Environment (iSee)
"FTIR-based fingerprinting of saliva for diabetic pregnant women" http://www.indjst.org
R. Raziya Sultana et al. Indian J.Sci.Technol. 
Probability $F$ one tail; $F$ critical value one tail. To calculate the $F$ value in which the test statistics has an $F$ distribution under the null hypothesis. In ANOVA, F-test was used to determine group of trial which differs significantly from an expected value.

Formula used

Sums of squares formula

$$
\begin{aligned}
& S S_{\text {total }}=\sum_{j=1}^{p} \sum_{i=1}^{n_{j}}\left(x_{i j}-\bar{x}\right)^{2} \\
& S S_{\text {between }}=\sum_{j=1}^{p} n_{j}\left(\bar{x}_{j}-\bar{x}\right)^{2} \\
& S S_{\text {within }}=\sum_{j=1}^{p} \sum_{i=1}^{n_{j}}\left(x_{i j}-\bar{x}_{j}\right)^{2}
\end{aligned}
$$

Mean squares Formula

$$
\begin{gathered}
M S_{\text {between }} \frac{S S_{\text {between }}}{d f_{\text {between }}} \\
M S_{\text {within }} \frac{S S_{\text {within }}}{d f_{\text {within }}}
\end{gathered}
$$

df is the degree of freedom

F Formula

$$
F=\frac{M S_{\text {between }}}{M S_{\text {between }}}
$$

Within instead of between in denominator

Thus, one way ANOVA calculator was used to test the equality of samples by using variance.

$F$ test for normal and diabetic pregnant women after insulin therapy (three hours and seven days) was observed using FTIR spectra (Table1-3)

\section{Interpretation of Table 7}

The interpretation of data in normal and diabetic pregnant women with insulin therapy (3hrs and 7 days) was analysed by the intensity test ratio on the sample collected using one way ANOVA method. The result of the insulin therapy as compared to the normal women as per the test hypothesis gives true factor as per the ratio of the two mean squares estimate the same quantity (error variance)using the FTIR spectra. The Effect of insulin using the ANOVA method was verified and mean result shows that the effect of insulin, was within the range of requirement of the Diabetic level control required for the patient through the saliva test within three hours and seven days from the period of insulin therapy. The result of insulin therapy was validated and found to be true in comparison with normal pregnant women.

$\mathrm{F}$ test for diabetic pregnant women before administration of insulin and after insulin therapy (three hours and seven days) was observed using FTIR spectra (Table 4$6)$
Interpretation of Table 8

Table 1. Squaring of the data -Anova method

\begin{tabular}{|c|c|c|c|c|c|}
\hline $\mathrm{x} 1$ & $\mathrm{x}^{2}$ & $\mathrm{x} 2$ & $\mathrm{x} 2^{2}$ & $\mathrm{x} 3$ & $\mathrm{x} 3^{2}$ \\
\hline 0.41 & 0.1680 & 0.42 & 0.1764 & 0.31 & 0.0960 \\
\hline 0.32 & 0.1024 & 0.32 & 0.1024 & 0.29 & 0.0841 \\
\hline 0.65 & 0.4225 & 0.79 & 0.6241 & 0.73 & 0.5328 \\
\hline 1.7 & 2.8899 & 1.5 & 2.25 & 1.5 & 2.25 \\
\hline 0.18 & 0.0324 & 0.21 & 0.0441 & 0.18 & 0.0324 \\
\hline
\end{tabular}

Table 2. Mean, Standard Deviation and Variance of pregnant women (normal and diabetic with insulin therapy).

\begin{tabular}{|c|c|c|c|c|}
\hline & $\mathrm{x} 1$ & $\mathrm{x} 2$ & $\mathrm{x} 3$ & Total \\
\hline Number $(\mathrm{n})$ & 5 & 5 & 5 & 15 \\
\hline$\Sigma \mathrm{x}$ & 3.2600 & 3.24 & 3.0100 & 9.51 \\
& & & & \\
\hline Mean & 0.652 & 0.648 & 0.6020 & 0.63 \\
\hline$\Sigma \mathrm{x}^{2}$ & 3.6153 & 3.1969 & 2.9955 & 9.8079 \\
\hline Variance & 0.37 & 0.27 & 0.30 & \\
\hline Std.Dev. & 0.608 & 0.520 & 0.548 & \\
\hline Std.Err. & 0.272 & 0.233 & 0.245 & \\
\hline
\end{tabular}
Table 3. Anova result

\begin{tabular}{|l|c|c|c|c|}
\hline & SS & df & MS & F \\
\hline Between & 0.0079 & 2 & 0.0040 & 0.0127 \\
\hline within & 3.7708 & 12 & 0.3142 & \\
\hline Total & 3.7788 & 14 & & \multicolumn{1}{|c}{} \\
\cline { 1 - 3 } & & & &
\end{tabular}

The insulin therapy (after $3 \mathrm{hrs}$ and 7 days therapy) used on the diabetic pregnant women was analyzed by the intensity test ratio on the sample collected using one way ANOVA method. The result of the insulin therapy as compared with diabetic pregnant women before administration of insulin, after three hours and seven days on diabetic pregnant women.

Table 4. Squaring of the data -Anova method

\begin{tabular}{|c|c|c|c|c|c|}
\hline $\mathrm{x} 1$ & $\mathrm{x}^{2}$ & $\mathrm{x} 2$ & $\mathrm{x} 2^{2}$ & $\mathrm{x} 3$ & $\mathrm{x}^{2}$ \\
\hline 0.68 & 0.4624 & 0.63 & 0.3969 & 0.47 & 0.2208 \\
\hline 0.45 & 0.2025 & 0.4 & 0.1600 & 0.39 & 0.1521 \\
\hline 0.8 & 0.6400 & 0.76 & 0.5776 & 0.72 & 0.5184 \\
\hline 0.69 & 0.4760 & 0.5 & 0.25 & 0.45 & 0.2025 \\
\hline 0.46 & 0.2116 & 0.32 & 0.1024 & 0.3 & 0.09 \\
\hline
\end{tabular}

Table 5. Mean, Standard Deviation and Variance of diabetic pregnant women

(before and after insulin therapy).

\begin{tabular}{|c|c|c|c|c|}
\hline & $\mathrm{x} 1$ & $\mathrm{x} 2$ & $\mathrm{x} 3$ & Total \\
\hline Number $(\mathrm{n})$ & 5 & 5 & 5 & 15 \\
\hline$\Sigma \mathrm{x}$ & 3.08 & 2.61 & 2.33 & 8.02 \\
& & & & \\
\hline Mean & 0.616 & 0.522 & 0.466 & 0.53 \\
\hline$\Sigma \mathrm{x}^{2}$ & 1.9926 & 1.4869 & 1.1839 & 4.6634 \\
\hline Variance & 0.02 & 0.03 & 0.02 & \\
\hline Std.Dev. & 0.141 & 0.173 & 0.141 & \\
\hline Std.Err. & 0.063 & 0.077 & 0.063 & \\
\hline
\end{tabular}

Table 6. Anova result

\begin{tabular}{|l|l|l|l|l|}
\hline & SS & df & MS & F \\
\hline Between & 0.0577 & 2 & 0.0289 & 1.0906 \\
\hline within & 0.3179 & 12 & 0.0265 & \\
\hline Total & 0.3756 & 14 & & \multicolumn{1}{|l}{} \\
\cline { 1 - 4 } & &
\end{tabular}

R. Raziya Sultana et al. Indian J.Sci.Technol.
Research article
CIndian Society for Education and Environment (iSee) 


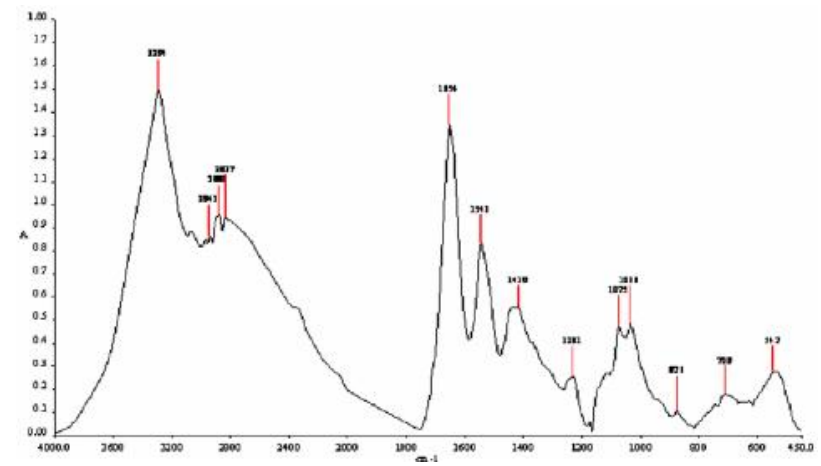

Fig. 1. FTIR spectrum of saliva of normal pregnant women

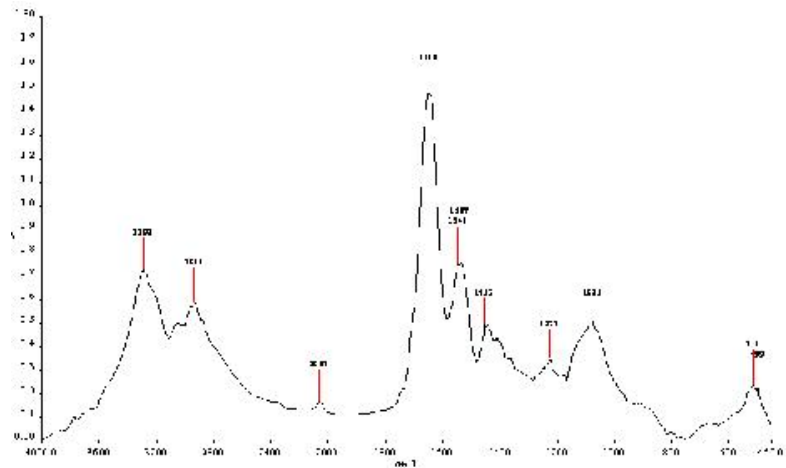

Fig.2. FTIR spectrum of saliva of Diabetic pregnant women

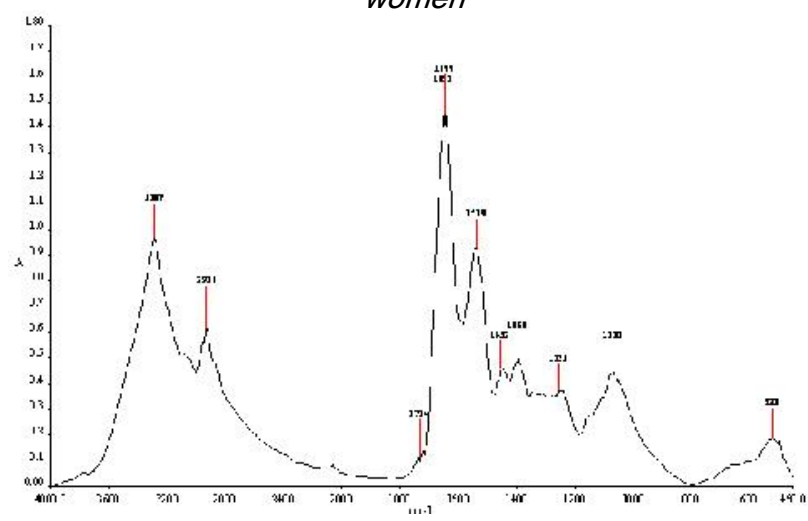

Fig.3. FTIR spectrum of saliva of Diabetic pregnant women (insulin therapy after $3 \mathrm{hrs}$ )

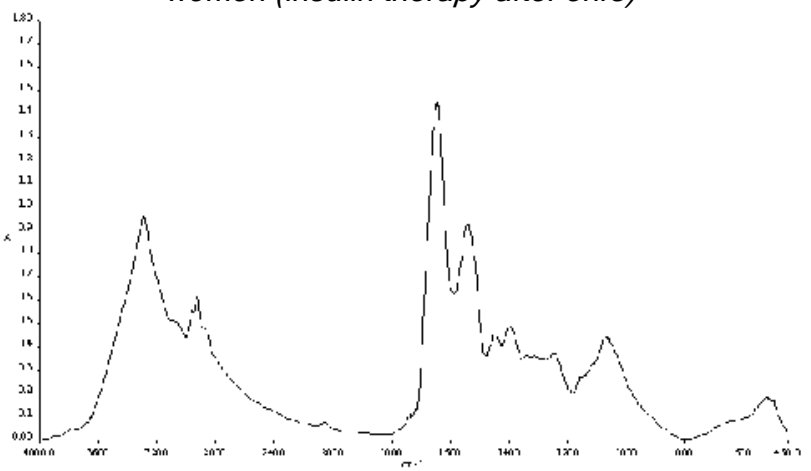

Fig.4. FTIR spectrum of saliva of Diabetic pregnant women (insulin therapy after 7 days)
Vol. 5 No. 3 (Mar 2012)

ISSN: 0974- 6846

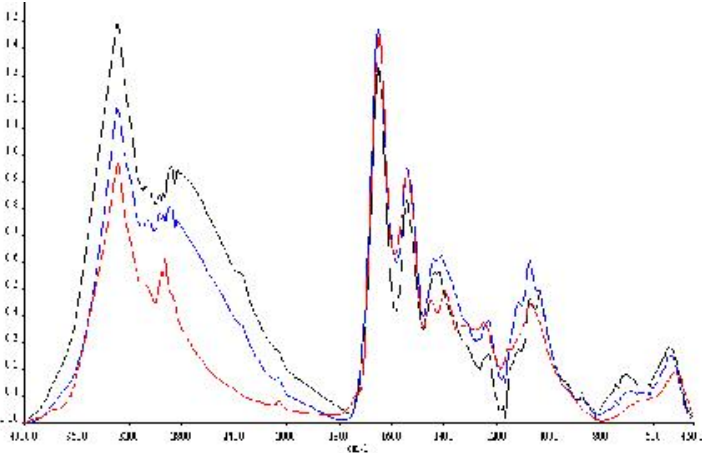

Fig. 5. Comparison of FTIR spectrum of saliva of normal pregnant women and with insulin therapy (after 3 hrs and 7 days)

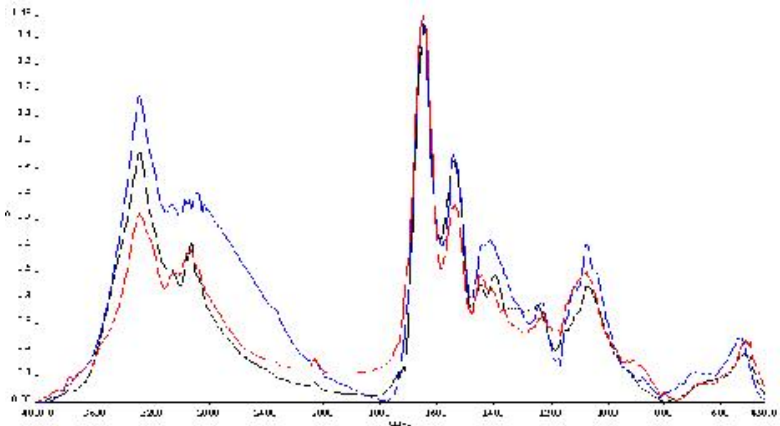

Fig.6. Comparison of FTIR spectrum of saliva of diabetic pregnant women and with insulin therapy (after 3hrs and 7 days).

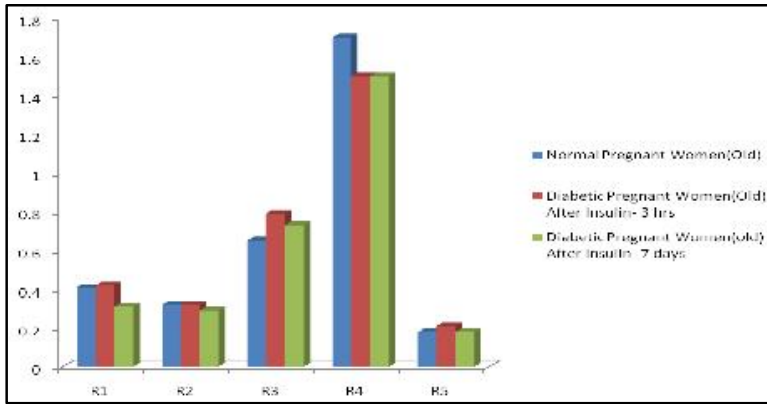

Fig. 7. Comparison of intensity ratio parameters of normal pregnant women and with diabetic insulin therapy (after 3hrs and 7 days).

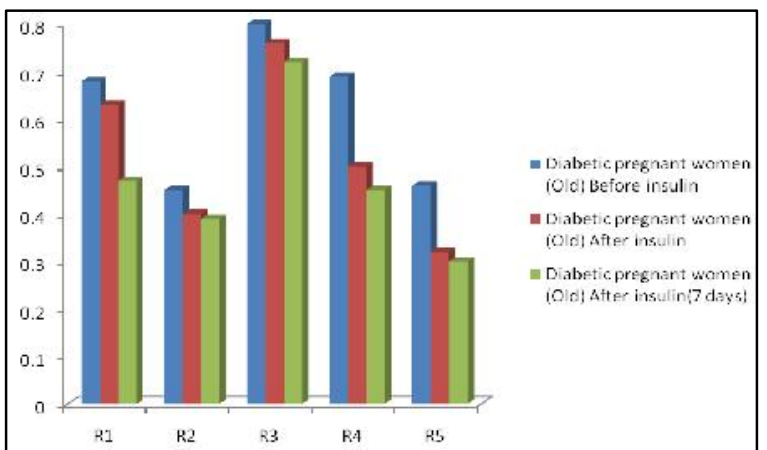

Fig.8. Comparison of intensity ratio parameters of diabetic pregnant women before administration of insulin and with insulin therapy (after 3hrs and 7 days).
Research article

CIndian Society for Education and Environment (iSee)
"FTIR-based fingerprinting of saliva for diabetic pregnant women" http://www.indjst.org
R. Raziya Sultana et al. Indian J.Sci.Technol. 
As per the test hypothesis it gave a true factor and as per the ratio of the two mean squares estimate using the FTIR spectra. The Effect of insulin using the ANOVA method was verified and mean result shows that the effect of insulin within the range of requirement of the Diabetic level control required for the patient was effected on a long term on the seventh day as compared to the immediate result of insulin therapy after three hours through the saliva test of insulin therapy on the patient. The Result of insulin response therapy was validated and found to be true in comparison with diabetic pregnant women.

\section{Results and discussion}

Oral mucosa has been suggested as an especially suited subject for drug delivery and monitoring of endogenous body metabolites due to histological and physic-chemical properties. FTIR spectroscopy as a bio diagnostic tool to predict changes occur during pregnancy. A representative FTIR absorption spectrum of saliva sample of normal pregnant women is shown in Fig. 1 and their vibrational band assignments with the idea of the group frequencies of the various analytes present in the sample are given in Table 7. Fundamental modes of vibration are identified for normal and diseased pregnant women and their absorbance values are noted. Internal standard at specific modes of vibration is calculated by finding the internal ratio of absorbance of the various bands. The chief organic constituents of saliva are mucin- a glycoprotein. An increase in the secretion of female sex hormones, estrogen by 10 -fold and progesterone by 30 -fold, is important for the normal progression of pregnancy. The characteristic vibrational peaks are mainly dominated by the protein constituents of the sample (Petibois et al., 2001; Deleris \& Petibois, 2003). Hetero aromatic containing an $\mathrm{N}-\mathrm{H}$ group show their stretching vibrations in the region $3500-3220 \mathrm{~cm}^{-1}$. The position of the absorption band in this region depends upon the degree of hydrogen bonding and hence upon the physical state of the sample or the polarity of the solvent. Primary amines examined in dilute solution display two weak absorption bands one near $3500 \mathrm{~cm}^{-1}$ and the other near $3400 \mathrm{~cm}^{-1}$. The appearance of the sharp band at $3377 \mathrm{~cm}^{-1}$ is assigned as $\mathrm{N}-\mathrm{H}$ stretching due to the immidazole ring in throphylline. In the present work, the band appearing at $3292 \mathrm{~cm}^{-1}$ is due to N-H stretching vibration. The peak at $2933-2923 \mathrm{~cm}^{-1}$ is attributed to $\mathrm{C}-\mathrm{H}$ stretching bands in malignant tissues (Wu et al.,2001) and the band appearing at $2931 \mathrm{~cm}^{-1}$ is due to asymmetric stretching $\mathrm{CH}_{2}$. The spectral region from $1630-700 \mathrm{~cm}^{-1}$ is due to amide I region and in the present work the peak observed at $1653 \mathrm{~cm}^{-1}$ is due to $\mathrm{C}=\mathrm{O}, \mathrm{C}=\mathrm{N}, \mathrm{N}-\mathrm{H}$ of adenine, thymine, guanine, cytosine (Dovbeshko et al., 1997). The spectral region (1500-1300 $\mathrm{cm}^{-1}$ ) is mainly dominated by the deformations of the methyl, methylene and C-H groups (Gunasekaran et al., 2007) and the band at $1547 \mathrm{~cm}^{-1}$ is due to aromatic ring stretching and the band at $1400-500 \mathrm{~cm}^{-1}$ is due to ring stretching vibration mixed strongly with $\mathrm{CH}$ in-plane bending (Schutz et al., 2007) and the observed peak at $1410 \mathrm{~cm}^{-1}$ is due to $(\mathrm{H}-\mathrm{C}-\mathrm{H})$ group.

The lipid contents of these compounds can be evaluated using peak intensity at $2956 \mathrm{~cm}^{-1}$ (asymmetric stretching vibration of $\mathrm{CH}_{3}$ of acyl chains), $2922 \mathrm{~cm}^{-1}$ (asymmetric stretching vibration of $\mathrm{CH}_{2}$ of acyl chains), $2874 \mathrm{~cm}^{-1}$ (symmetric stretching vibration of $\mathrm{CH}_{3}$ of acyl chains), $2852 \mathrm{~cm}^{-1}$ (symmetric stretching vibration of $\mathrm{CH}_{2}$ of acyl chains), and $1600-1800 \mathrm{~cm}^{-1}$ ( $\mathrm{C}=\mathrm{O}$ stretching). The specifications of protein contents of biological samples can also be understood from $1717 \mathrm{~cm}^{-1}$ (amide I, arising from $\mathrm{C}=\mathrm{O}$ stretching vibration), $1500-600 \mathrm{~cm}^{-1}$ (amide II, N-H bending vibration coupled to C-N stretching), and $1220-1350 \mathrm{~cm}^{-1}$ (amide III, C-N stretching and $\mathrm{N}-\mathrm{H}$ in plane bending, often with significant contributions from $\mathrm{CH}_{2}$ wagging vibrations). The peaks related to nucleic acids are as follows: $1717 \mathrm{~cm}^{-1}(\mathrm{C}=\mathrm{O}$ stretching vibration of purine base), $1666 \mathrm{~cm}^{-1}$ ( $C=0$ stretching vibration of pyrimidine base), $1220-1240 \mathrm{~cm}^{-1}$ (asymmetric $\mathrm{PO}_{2}$ stretching), $1117 \mathrm{~cm}^{-1}$ (C-O stretching vibration of $\mathrm{C}-\mathrm{OH}$ group of ribose), $1040-100 \mathrm{~cm}^{-1}$ (symmetric stretching of phosphate groups of phosphodiester linkages), and 1050-70 $\mathrm{cm}^{-1}$ (C-O-C stretching) (Fabian et al., 1995). Hetero aromatic containing an $\mathrm{N}-\mathrm{H}$ group shows their stretching vibrations in the $3500-3220 \mathrm{~cm}^{-1}$ and in the present work it is observed at $3292 \mathrm{~cm}^{-1}$. The peak at $2933 \mathrm{~cm}^{-1}$ is due to $\mathrm{C}-\mathrm{H}$ stretching vibration in malignant tissues $\mathrm{Wu}$ etal.,2001) and the band appearing at $2931 \mathrm{~cm}^{-1}$ is due to asymmetric stretching of $\mathrm{CH}_{2}$, whereas the progesterone is observed in the region $1690-1620 \mathrm{~cm}^{-1}$ (John et al.,2005). The spectral region from $1630-700 \mathrm{~cm}^{-1}$ is due to Amide I region and in the present work the peak is observed at $1653 \mathrm{~cm}^{-1}$ is due to $\mathrm{C}=\mathrm{O}, \mathrm{C}=\mathrm{N}, \mathrm{N}-\mathrm{H}$ of adenine, thymine, guanine, cytosine (Dovbeshko et al.,1997). The peak at $1544 \mathrm{~cm}^{-1}$ is due to Amide II bands (arises from C-N stretching \& $\mathrm{CHN}$ bending vibrations (Huleihel et al.,2002). and the observed peak at $1410 \mathrm{~cm}^{-1}$ is due to $(\mathrm{H}-\mathrm{C}-\mathrm{H})$. The prominent absorption peak is at $1224 \mathrm{~cm}^{-1}$ is due to symmetric stretching of phosphate groups in phospholipids (Fabian et al., 1995). The glucose or sugar moieties are found to be observed at $950-1180 \mathrm{~cm}^{-1}$, in present work the peak is observed at $1075 \mathrm{~cm}^{-1}$ due to glucose and the band at $1075 \mathrm{~cm}^{-1}$ is due to $\mathrm{C}-\mathrm{N}$ stretching absorption of aliphatic amines is weak.

FTIR spectra show significant spectral differences between the normal pregnant women and change in saliva of diabetic pregnant women with insulin therapy i.e., after insulin (3hrs) and after insulin (7days) of pregnant women. In order to quantify the results further five intensity ratio parameters $R_{1}\left(I_{1653} / I_{1410}\right), R_{2}\left(I_{2931} / I_{547}\right)$, $\mathrm{R}_{3}\left(\mathrm{I}_{2931} / \mathrm{I}_{1410}\right), \quad \mathrm{R}_{4}\left(\mathrm{I}_{2931} / \mathrm{I}_{3292}\right), \mathrm{R}_{5}\left(\mathrm{I}_{3292} / \mathrm{I}_{547}\right)$ are calculated. The results observed for diabetic pregnant women after insulin therapy (i.e., $3 \mathrm{hrs}$ and 7 days) is more or less similar to that of the normal pregnant women. 
Table 7. Comparison of normal and diabetic pregnant women with insulin therapy

\begin{tabular}{|l|l|l|l|}
\hline \multirow{2}{*}{ Intensity ratio } & \multicolumn{3}{|c|}{ Old( $3^{\text {rd }}$ trimester) } \\
\cline { 2 - 4 } & $\begin{array}{c}\text { Normal } \\
\text { pregnant } \\
\text { women } \\
\text { (Old) }\end{array}$ & $\begin{array}{c}\text { Diabetic } \\
\text { pregnant } \\
\text { women(Old) } \\
\text { After insulin- } \\
3 \text { hours }\end{array}$ & $\begin{array}{c}\text { Diabetic } \\
\text { pregnant } \\
\text { women(Old) } \\
\text { After insulin- } \\
7 \text { days }\end{array}$ \\
\hline $\mathrm{R}_{1}\left(\mathrm{I}_{1653} / \mathrm{I}_{1410}\right)$ & 0.41 & 0.42 & 0.31 \\
\hline $\mathrm{R}_{2}\left(\mathrm{I}_{2931} / \mathrm{I}_{547}\right)$ & 0.32 & 0.32 & 0.29 \\
\hline $\mathrm{R}_{3}\left(\mathrm{I}_{2931} / \mathrm{I}_{1410}\right)$ & 0.65 & 0.79 & 0.73 \\
\hline $\mathrm{R}_{4}\left(\mathrm{I}_{2931} / \mathrm{I}_{3292}\right)$ & 1.7 & 1.5 & 1.5 \\
\hline $\mathrm{R}_{5}\left(\mathrm{I}_{3292} / \mathrm{I}_{547}\right)$ & 0.18 & 0.21 & 0.18 \\
\hline
\end{tabular}

Fig.2 presents the spectrum of diabetic pregnant women and infrared spectra of change in saliva of diabetic after insulin therapy ( $3 \mathrm{hrs}$ and 7 days) are shown in the (Figs. 3-4). In order to quantify the results further five intensity ratio parameters $R_{1}\left(I_{1544} / I_{1075}\right), R_{2}$ $\left(I_{1544} / I_{1224}\right), R_{3}\left(I_{2931} / I_{1075}\right), R_{4}\left(I_{3292} / I_{1075}\right), R_{5}\left(I_{3292} / I_{1224}\right)$, are calculated and the observed absorbance values increases in diabetic pregnant women and slight decrease in diabetic after insulin therapy $3 \mathrm{hrs}$ and further decreases after 7 days. Fig.5 shows the comparison of normal pregnant women and diabetic with insulin therapy after $3 \mathrm{hrs}$ and 7 days and also the comparison of diabetic pregnant women before and after therapy as shown in Fig.6. Table 8 gives the intensity ratio calculation and the variation of bar diagram shown in (Fig. 7-8).

\section{Analysis with Histogram}

The bar diagram shown in Fig. 7 and Fig 8 between the intensity ratio parameters and absorbance values were obtained from the FTIR spectra. From the histogram (Fig.7) shows a striking spectral difference between the saliva of normal pregnant women with diabetic after insulin therapy $3 \mathrm{hrs}$ and after 7 days. Also the Fig. 8 shows that there is a change in the absorbance value of the diabetic pregnant women with insulin therapy after 3 hrs and after 7 days.

Table 8. Intensity ratio parameter of diabetic pregnant women with insulin therapy of higher age group

\begin{tabular}{|l|l|l|l|}
\hline \multirow{2}{*}{$\begin{array}{c}\text { Intensity } \\
\text { ratio }\end{array}$} & \multicolumn{3}{|c|}{ Diabetic pregnant women (old) } \\
\cline { 2 - 4 } & $\begin{array}{c}\text { Before } \\
\text { insulin }\end{array}$ & \multicolumn{1}{|c|}{$\begin{array}{c}\text { After insulin } \\
(3 \mathrm{hrs})\end{array}$} & \multicolumn{1}{|c|}{$\begin{array}{c}\text { After insulin } \\
\text { (7 days) }\end{array}$} \\
\hline $\mathrm{R}_{1}\left(\mathrm{I}_{1544} / \mathrm{I}_{1075}\right)$ & 0.68 & 0.63 & 0.47 \\
\hline $\mathrm{R}_{2}\left(\mathrm{I}_{1544} / \mathrm{I}_{1224}\right)$ & 0.45 & 0.4 & 0.39 \\
\hline $\mathrm{R}_{3}\left(\mathrm{I}_{2931} / \mathrm{I}_{1075}\right)$ & 0.8 & 0.76 & 0.72 \\
\hline $\mathrm{R}_{4}\left(\mathrm{I}_{3292} / \mathrm{I}_{1075}\right)$ & 0.69 & 0.5 & 0.45 \\
\hline $\mathrm{R}_{5}\left(\mathrm{I}_{3292} / \mathrm{I}_{1224}\right)$ & 0.46 & 0.32 & 0.3 \\
\hline
\end{tabular}

\section{Conclusion}

Role of FTIR spectroscopic techniques in the analysis of saliva of normal and diabetic pregnant women before administration of insulin and after insulin therapy (3 hrs and 7 days) are clearly demonstrated both qualitatively and quantitatively. The absorption of the vibrational peaks of diabetic pregnant women after administrating insulin ( $3 \mathrm{hrs}$ and 7 days) is similar to that of normal pregnant women. However, the intensity of absorption peaks of the diabetic pregnant women before administration of insulin increases and decreased after intake of insulin (3hrs) and further decreased after insulin therapy ( 7 days). Thus, striking spectral differences in terms of intensity values were observed between saliva of normal, diseased subjects. This work exhibits how saliva by non-invasive sampling can be used to distinguish between 2 different sample categories (diabetic pregnant women from that of normal pregnant women).

\section{References}

1. Chaita TM, Graham SM, Maxwell SM, Sirivasin W, Sabchareon A and Beeching NJ (1995) Salivary sampling for hepatitis B surface antigen carriage: A sensitive technique suitable for epidemiological studies. Ann. Trop. Paediatr. Saliva \& Early Detection of Diseases. 247 (15), 135-139.

2. Cone EJ (1993) Saliva testing for drugs of abuse. Ann. NY Acad. Sci. 694, 91-127.

3. Deleris G and Petibois C (2003) Applications of FTIR spectrometry to plasma contents analysis and monitoring. Vibrational Spec. 32, 129.

4. Dovbeshko Gl, Girdina NY, kruglova EB and Pashchuk OP (1997) FTIR Spectroscopy studies of nucleic acid damage. Talanta. 53, 233-246.

5. El-Medany OM, El-Din Abdel Wahab KS, Abu Shady EA and Gad El-Hak N (1999) Chronic liver disease and hepatitis $\mathrm{C}$ virus in Egyptian patients. Hepatogastroenterol. 46,1895-1903.

6. Emmons W (1997) Accuracy of oral specimen testing for human immunodeficiency virus. Am. J. Med. 102,15-20.

7. Fabian $\mathrm{H}$, Jackson $\mathrm{M}$, Murphy $\mathrm{L}$, Watson $\mathrm{PH}$, Fichtner I and Mantsch HH (1995) A comparative infrared spectroscopic study of human breast tumors and breast tumor cell xenografts. Biospectroscopy. 1 (1), 37-45.

8. Frank W, Ling and Patrick Duff (2004) Obstetrics and gynecology principle for practice. Mc Graw - Hill Medical Publ. Div., ISBN 0-8385-7201-4

9. Huleihel M, Salman A, Erukhimovich V, Ramesh J, Hammody Z and Mordechai S (2002) Novel optical method for study of viral carcinogenesis in vitro. J. Biochem. Biophy. Met. 50, 111-121.

10.Gunasekaran, Devi TSR and Sakthivel PS (2007) FTIR, FT Raman and UV-Visible spectral measurements and analysis on Atorvastatin Calcium. Asian J. Chem. 19 (1), 335-346.

11.John FR (Greenville DE, US) and Mei-wei T (Wilmington, DE, US) (2005) IR spectrographic apparatus and method for diagnosis of disease, United States patent application 20090118601

12.Kidwell DA, Holland JC and Athanaselis S (1998) Testing for drugs of abuse in saliva and sweat $J$. Chromatogr. B Biomed. Sci. Appl. 713, pp:111-135.

13. Malamud D (1997) Oral diagnostic testing for detecting human immune deficiency virus-1
Research article

COIndian Society for Education and Environment (iSee)
"FTIR-based fingerprinting of saliva for diabetic pregnant women" http://www.indjst.org
R. Raziya Sultana et al. Indian J.Sci.Technol. 
antibodies: A technology whose time has come. Am. J. Med.102, 9-14.

14. Mandel ID (1993) A contemporary view of salivary research. Crit. Rev. Oral Biol. Medical. 4, 599-604.

15.Nussey S and Whitehead S (2001) Endocrinology. An Integrated Approach. Oxford: BIOS Scientific Publishers [London: Taylor \& Francis]. Also found online at http://www.ncbi.nlm.nih.gov/books/bv.fcgi?rid=endocri n. TOC\&depth $=1$.

16. Ochnio JJ, Scheifele DW, Ho $M$ and Mitchell LA (1997) New, ultra-sensitive enzyme immunoassay for detecting vaccine- and disease-induced hepatitis $A$ virus specific immunoglobulin $G$ in saliva. J. Clin. Microbiol. 35, 98-101.

17.Petibois C, Cazorla G, Cassaigne A, Perromat A and Deleris G (2001) Plasma protein contents determined by Fourier-Transform infrared spectrometry. Clinical Chem. 47, 730-738.

18.Raziya Sultana R, Zafarullah SN, Hephzibah Kirubamani N (2011) Utility of FTIR spectroscopic analysis of saliva of Diabetic pregnant women in each trimester. Indian J. Sci. Technol. 4 (8), 967-970.

19.Rehak NN, Cecco SA and Csako G (2000) Biochemical composition and electrolyte balance of "unstimulated" whole human saliva. Clin. Chem. Lab. Med. 38, 335-343.

20.Schultz CP, Ahmed MK, Dawes C and Mantsch HH (1996) Thiocyanate levels in human saliva: quantitation by Fourier transform infrared spectroscopy. Anal. Biochem. 240 (1),7-12.

21.Slavkin HC (1998) Toward molecularly based diagnostics for the oral cavity. J. Am. Dent. Assoc. 129, 1138-1143.

22. Tilakaratne A, Soory M, Ranasinghe AW, Corea SM, Ekanayake SL and de Silva M (2000) Periodontal disease status during pregnancy and 3 months postpartum in rural population of Sri-Lankan women. $J$. Clin. Periodontol. 27, 787-92.

23. Wu JG, Xu YZ, Sun CW, Soloway RD, Xu DF, Wu QG, Sun KH, Weng SF and $X u$ GX (2001) Distinguishing malignant from normal oral tissues using FTIR fiber-optic techniques. Biopolymer (Biospectroscopy). 62, 185-192.

24.Zelles T, Purushotham KR, Macauley SP, Oxford GE and Humphreys-Beher MG (1995) Saliva and growth factors: The fountain of youth resides in us all. J. Dent. Res. 74, 1826-1832. 